\title{
New insights into immunological aspects of atherosclerosis
}

\author{
Jacek Jawień \\ Pharmacology Department, Jagiellonian University School of Medicine, Kraków, Poland
}

\begin{abstract}
Although atherosclerosis was previously thought to be mainly a degenerative disease, it is now well ascertained that its pathogenesis is inflammatory. This review describes the history of a new atherogenetic concept, including the pivotal role of apoE-knockout mice in understanding the inflammatory background of atherosclerosis. There has been lack of unequivocal evidence of an important inflammatory component in atherogenesis. This evidence was delivered by a new technique - gene targeting, for the invention of which Mario R. Capecchi, Martin J. Evans and Oliver Smithies received in 2007 the Nobel Prize in Physiology or Medicine. The pivotal stage of atherogenesis is the antigen presentation by macrophages to T lymphocytes. This antigen could be a fragment of oxidized low-density lipoproteins "digested" by macrophage, heat shock protein $60, \beta_{2}$-glycoprotein I or fragments of bacterial antigens. For interaction between the immunological cells a presence of CD40 receptor on macrophages and its ligand CD40L on the surface of T lymphocytes are necessary. During the interaction between these cells an immunological type T helper 1 (Th1 - cellular) or T helper 2 (Th2 - humoral) response arises. Th1 response and its mediators: interferon $\gamma$, tumor necrosis factor $\alpha$, interleukin-1, interleukin-12 and interleukin-18 enhance atherogenesis, whereas Th2 response and its mediators: interleukin-4, interleukin-5, interleukin-10 and interleukin-13 inhibit the development of atherosclerosis. Atherosclerosis is therefore a chronic inflammatory disease, in most cases initiated by hypercholesterolemia. Nowadays, hypercholesterolemia and inflammation are considered as "partners in crime". The concept of atherosclerosis as inflammatory disease is fairly new, however, it is already considered as an undisputable achievement of science which have particular therapeutic consequences.
\end{abstract}

Key words: atherogenesis, atherosclerosis, immunity, inflammation

\section{INTRODUCTION}

Studies concerning the pathogenesis of atherosclerosis entered a new phase at the turn of the 21st century. The 20th century was the age of cholesterol and lipoproteins, which has been concluded in a number of clinical studies carried out on a large scale, and they demonstrated unequivocally that normalization of hypercholesterolemia significantly decreased the incidence and mortality of coronary artery disease [1,2]. Nearly to the end of the nineties, atherosclerosis had been assumed to develop as the so-called chronic response to injury (responseto-injury hypothesis) that resulted in the loss of endothelial cells which line the inner side of the vessels [3]. However, other studies showed that the endothelial cells covering the early atheromatous changes were in reality intact [4].

Correspondence to:

Asocc. Professor Jacek Jawień, MD, PhD, Katedra Farmakologii, Collegium Medicum Uniwersytetu Jagiellońskiego, ul. Grzegórzecka 16, 31-531 Kraków, Poland, phone: +48-12-421-11-68, fax: +48-12-421-72-17, e-mail: mmjawien@cyf-kr.edu.pl Received: December 31, 2007. Accepted in final form: January 22, 2008. Conflict of interest: none declared.

Pol Arch Med Wewn. 2008; 118 (3): 127-131

Translated by Izabela Jastrzębska, MD, PhD

Copyright by Medycyna Praktyczna, Kraków 2008
Thus, atherosclerosis had been considered first of all a degenerative disease [5-7]. However, approximately 20 years ago, the trials started to focus to a large extent on another pathogenetic mechanism of atherosclerosis, not considered so far - the inflammatory process.

\section{The first indications}

In 1986, with the use of monoclonal antibodies, the small cells with round nucleus present in the atheromatous plaque, known before as "small monocytes", were demonstrated to be T lymphocytes [8]. Several years later it was shown that these lymphocytes "recognize" as antigens the oxidized molecules of low-density lipoproteins (LDL) - oxLDL [9].

Moreover, the correlation between atherosclerosis and the presence of at least two types of infectious microorganisms; Chlamydia pneumoniae and herpes simplex virus was observed $[10,11]$. It raised the question if the inflammatory process participate in atherosclerosis. Speculations of this kind were initially received with great scepticism because there was no spectacular and unequivocal evidence of a significant role of inflammation in atherosclerosis. 
This evidence was delivered by a new technique - gene targeting, for the invention of which Mario R. Capecchi (Italy), Martin J. Evans (United Kingdom) and Oliver Smithies (USA) received the Nobel Prize in Physiology or Medicine in 2007.

\section{Additional evidence for the presence of inflammation in atherosclerosis}

The newest model of atherosclerosis (described precisely at the end of the paper) enabled the investigators to create apoEknockout mice, an ideal animal model to test the influence of singular proteins participating in the inflammatory response on the development of atherosclerosis. These studies showed, for example, that the absence of only one cytokine - interferon $\gamma$ (IFN- $\gamma$ ), reduced atherosclerosis even by 60\% [12]. The overexpression of adhesive molecules (vascular adhesion molecule 1 and intercellular adhesion molecule 1) at sites with atheromatous changes was also observed in apoE-knockout mice [13]. Monocyte chemotactic protein was shown to play an important part in the progression of atheromatous lesions $[14,15]$. Moreover, it was observed that interleukin-18 knockout decreased atherosclerosis by $35 \%[16,17]$.

Inhibition of CD40 signaling reduced atherosclerosis [18]. This was explained by the fact that ligation of CD 40 molecule (tumor necrosis factor $\alpha$ [TNF- $\alpha]$ receptor superfamily member) - found in the atheromatous plaque, on endothelial cells, vascular smooth muscle cells, antigen-presenting cells, platelets - with CD $40 \mathrm{~L}$ activates a number of transcription factors: NF-кB, AP-1, STAT-1 or Egr-1. Therefore, it influences, for example, the endothelial cell, which, in consequence, acquires proinflammatory and proatherosclerotic phenotype leading to the expression of adhesive molecules and tissue factor on its surface. It creates new possibilities of therapeutic approach, consisting in inhibition of the CD40-CD40L pathway [19-21]. In mice the effect of CD 40 is also antagonized by transforming growth factor $\beta$ [22].

Finally, in apoE-knockout mice with severe combined immunodeficiency (SCID) atherosclerosis was reduced by $70 \%$ in comparison to the control group, due to a significantly lower number of lymphocytes in mice with SCID. It was demonstrated that transfer of $\mathrm{T}$ cells to these mice aggravated atherosclerosis even by $164 \%$ [23].

\section{Atherosclerosis as an inflammatory process}

These and other facts made the investigators realize unequivocally that inflammation was essential for atherogenesis. Therefore, in 1999, just before his death, Russell Ross (the author of the previous theory of atherosclerosis as a chronic response to injury) officially proclaimed that atherosclerosis was an inflammatory disease [24].

Whereas the deposition of atheromatous lipids and the accumulation of foam cells - macrophages filled with such lipids - in intima is the main morphological hallmark of atherosclerosis, the more subtle changes in the environment of the arterial wall, stimulated by the influx of inflammatory cells and local release of cytokines and other inflammatory mediators are currently recognized as the crucial causative factors of atherogenesis [25,26].

Inflammation occurs in response to a factor that destabilizes the local homeostasis. The factors that cause Toll-like receptor dependent macrophage activation in the arterial wall include oxLDL, heat shock protein 60 (HSP60) and bacterial toxins [27].

The first stage of atherogenesis consists in endothelial dysfunction [24]. It involves first of all the regions of arterial bifurcations where the blood flow is not laminar. Hence, these localizations are prone to develop atherosclerosis. In such places LDL is stored in the subendothelial space. Low-density lipoprotein accumulation is increased if serum LDL level is elevated. Low-density lipoprotein is transported by passive diffusion and its accumulation in the vascular wall seems to depend on the interaction between apolipoprotein B of the LDL molecule and proteoglycans of the matrix [28].

There is evidence that unchanged LDL are "collected" by the macrophages too slowly to activate their transformation into foam cells. Therefore, it has been suggested that LDL molecule is "modified" in the vascular wall. The most significant modification is lipid oxidation, resulting in the formation of so-called "minimally oxidized" LDL [29]. The generation of these "aliens" for the body molecules leads to the development of inflammatory response, with participation of monocytes and lymphocytes in the first place [30,31].

The inflammation is triggered by accumulation of the minimally oxidized LDLs in the subendothelial space, thus stimulating the endothelial cells to produce a number of proinflammatory molecules [32].

Before the "minimally oxidized" LDL have been phagocytised by the macrophages, they have to be modified into "highly oxidized" LDL. The scavenger receptors are responsible for the rapid uptake of the modified LDL [33].

During the following phase macrophages "present the antigen" to T lymphocytes. This antigen may be a fragment of oxidized LDL "digested" by the macrophages (Fig.), HSP60, $\beta_{2}$-glycoprotein I or the fragments of bacterial antigens [34].

The interaction between the immunological cells requires the presence of CD40 receptor on the surface of macrophages and its ligand CD40L on the surface of $\mathrm{T}$ lymphocytes $[35,36]$. The reciprocal action of these cells produces the immunological response of type $\mathrm{T}$ helper 1 (Th1 - cellular) or of type T helper 2 (Th2 - humoral). It is currently believed that the immunological response of Th1 type and its mediators: IFN- $\gamma$, TNF- $\alpha$, interleukin-1, interleukin-12 as well as interleukin-18 accelerate atherosclerosis, whereas the response of Th2 type and its mediators: interleukin-4, interleukin-5, interleukin-10 as well as interleukin-13 inhibit the development of atherosclerosis [37-39]. Therefore, there has arisen an idea of vaccination as a future treatment against atherogenesis [40].

The next phase of atherogenesis is the development of fibrous atheroma. The deposition of extracellular cholesterol 
and its esters is then intensified as well as the migration of smooth muscle cells from media to intima, proliferation of these cells and finally production of the extracellular matrix by the smooth muscles cells.

A stable atheromatous plaque is most commonly covered with a fairly thick fibrous layer, protecting the lipid nucleus from contact with the blood. In an unstable plaque there is a big lipid nucleus with a fairly thin fibrous layer. In atheromatous plaque, changed as described above, the proinflammatory factors produced by $\mathrm{T}$ lymphocytes (such as IFN- $\gamma$ ) seem to play a crucial role. They decrease production of the extracellular matrix by smooth muscles and at the same time increase production of the metalloproteinases by macrophages [41].

\section{Is atherosclerosis an autoimmunological disease?}

The role of HSP60 as an initiator of atherogenesis is currently intensively investigated. Its "molecular mimicry" with HSP of Chlamydia has been observed [42]. Moreover, the anti-oxLDL antibodies resemble antiphospholipid antibodies, therefore the concept of atherosclerosis as an autoimmunological disease has been established $[34,43,44]$. The investigators also emphasize a high pathogenetic similarity of atherosclerosis to rheumatoid arthritis [45].

\section{The newest experimental model of atherosclerosis}

Since 1992 the mouse has become an excellent object for the studies on atherosclerosis, replacing the previous animal models [46-48]. Then, the first line of mice with a switchedoff gene for apolipoprotein E (apoE-knockout) was developed almost contemporaneously in two laboratories in the United States [49,50]. These mice were soon described as "reliable and useful, the best animal model of atherosclerosis in present times" [51].

During the generation of apoE-knockout mice (known also as apoE null or apoE deficient mice) the normal gene coding apolipoprotein $\mathrm{E}$ is replaced by a mutated gene which does not produce this molecule. Such mice are called apoEknockout because they have a knockout, switched-off, null or inactivated gene coding apolipoprotein E. For clarity, in the following sections of this paper we will use the most popular name: apoE-knockout mice.

The year 1992, in which apoE-knockout mice were invented by a homological exchange of genes, was a real breakthrough year in the studies on the pathogenesis of atherosclerosis [52].

The apoE-knockout mice were formed by homological recombination of embryonic stem cells. The changed cells were implanted into the blastocyst of a mouse of $\mathrm{C} 57 \mathrm{BL} / 6 \mathrm{~J}$ strain which were subsequently implanted into the uterus. The offspring was a "chimera" that was next crossbred with a mouse

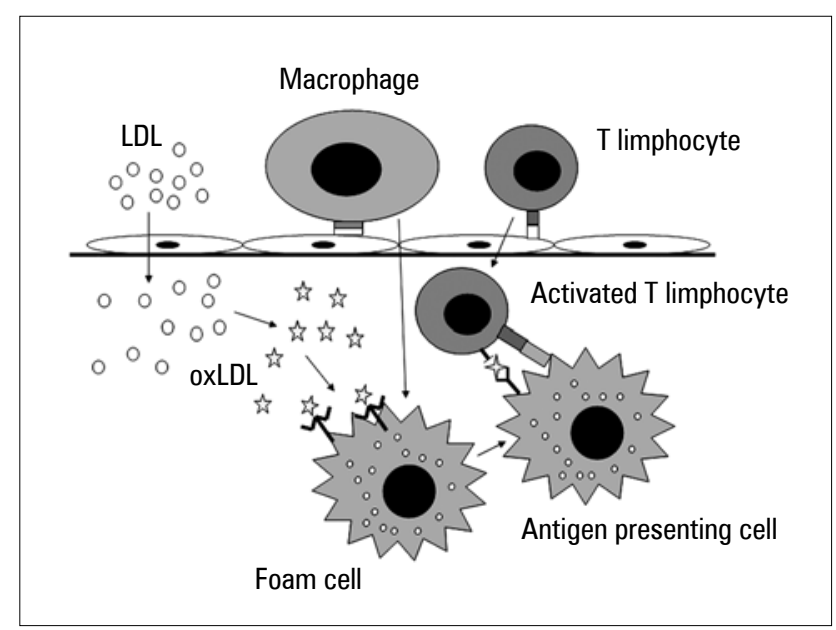

Fig. The initial stage of atherogenesis. Low-density lipoprotein (LDL) molecules after crossing the endothelial barrier and penetrating into the subendothelial space are trapped and oxidized there to oxidized LDL (oxLDL), becoming a foreign antigen for the organism. Foam cells trap the oxLDL molecules with the use of scavenger receptors. The oxLDL molecule is then digested and transformed, and is presented to T lymphocyte, initiating the classic immunological reaction that is a stimulus of the inflammatory response

of $\mathrm{C} 57 \mathrm{BL} / 6 \mathrm{~J}$ strain (wild type), which led to the formation of apoE-knockout, homozygous mice in the second generation [53]. The inactivation of the gene coding apoE resulted in the formation of mice with a phenotype with a complete suppression of apoE, but with preservation of fertility and vitality [54]. The apoE-knockout mice, in contrast to all of other animal models, develop atherosclerosis spontaneously, without high-cholesterol diet [55].

The generation of such a model changed the nature of the studies on the pathogenesis of atherosclerosis and enabled the investigators to formulate a new definition of atherosclerosis as a chronic inflammation [52].

\section{SUMMARY}

In a number of reports on atherogenesis published so far there has been a tendency to consider this process as the effect of dyslipidemia or inflammation alone. It is an erroneous dichotomy. It should be emphasized that atherosclerosis results from both lipid disorders and enhanced inflammation.

Therefore, atherosclerosis is a chronic inflammatory disease, in most cases initiated and aggravated by hypercholesterolemia. In the review published in Nature Medicine hypercholesterolemia and inflammation were described as "partners in crime" [56].

The inflammatory concept of atherosclerosis has been formulated just in the recent years. However, it is currently an unquestionable achievement of science which also have specific therapeutic implications [57-62]. 


\section{REFERENCES}

1. Prevention of cardiovascular events and death with pravastatin in patients with coronary heart disease and a broad range of initial cholesterol levels. The Long-Term Intervention with Pravastatin in Ischaemic Disease (LIPID) Study Group. N Engl J Med. 1998; 339: 1349-1357

2. Scandinavian Simvastatin Survival Study Group. Randomised trial of cholesterol lowering in 4444 patients with coronary heart disease: The Scandinavian Simvastatin Survival Study (4S). Lancet. 1994; 344: 1383-1389.

3. Ross R, Glomset JA. The pathogenesis of atherosclerosis. N Engl J Med. 1976; 295: 369-377.

4. Davies PF, Reidy MA, Goode TB, Bowyer DE. Scanning electron microscopy in the evaluation of endothelial integrity of the fatty lesion in atherosclerosis. Atherosclerosis. 1976; 25: 125-130.

5. Ross R, Glomset J, Harker L. Response to injury and atherogenesis. Am J Pathol 1977; 86: 675-684.

6. Ross R, Faggiotto A, Bowen-Pope D, Raines E. The role of endothelial injury and platelet and macrophage interactions in atherosclerosis. Circulation. 1984; 70: 77-82.

7. Ross R. The pathogenesis of atherosclerosis - an update. New Engl J Med. 1986 314: 488-500.

8. Jonasson L, Holm J, Skalli 0, et al. Regional accumulations of T cells, macrophages, and smooth muscle cells in the human atherosclerotic plaque. Arteriosclerosis 1986; 6: 131-138.

9. Stemme S, Faber B, Holm J, et al. T lymphocytes from human atherosclerotic plaques recognize oxidized low density lipoprotein. Proc Natl Acad Sci USA. 1995; 92: 3893-3897.

10. Thom DH, Wang SP, Grayston JT, et al. Chlamydia pneumoniae strain TWAR antibody and angiographically demonstrated coronary artery disease. Arterioscle Thromb. 1991; 11: 547-551.

11. Hendrix MG, Salimans MM, van Boven CP, Bruggeman CA. High prevalence of latently present cytomegalovirus in arterial walls of patients suffering from grade III atherosclerosis. Am J Pathol. 1990; 136: 23-28.

12. Gupta $S$, Pablo AM, Jiang $X$, et al. IFN-gamma potentiates atherosclerosis in ApoE knock-out mice. J Clin Invest. 1997; 99: 2752-2761.

13. Nakashima Y, Raines EW, Plump AS, et al. Upregulation of VCAM-1 and ICAM-1 a atherosclerosis-prone sites on the endothelium in the ApoE-deficient mouse. Arterioscler Thromb Vasc Biol. 1998; 18: 842-851.

14. Aiello RJ, Bourassa PA, Lindsey $S$, et al. Monocyte chemoattractant protein-1 accelerates atherosclerosis in apolipoprotein E-deficient mice. Arterioscler Thromb Vasc Biol. 1999; 19: 1518-1525.

15. Ni W, Egashira K, Kitamoto S, et al. New anti-monocyte chemoattractant protein-1 gene therapy attenuates atherosclerosis in apolipoprotein E-knockout mice. Circulation. 2001; 103: 2096-2101.

16. Elhage $R$, Jawien J, Rudling $M$, et al. Reduced atherosclerosis in interleukin-18 deficient apolipoprotein E-knockout mice. Cardiovasc Res. 2003; 59: 234-240.

17. Tenger C, Sundborger A, Jawien J, Zhou X. IL-18 accelerates atherosclerosis accompanied by elevation of IFN-gamma and CXCL16 expression independently of cells. Arterioscler Thromb Vasc Biol. 2005; 25: 791-796.

18. Mach F, Schönbeck U, Sukhova GK, et al. Reduction of atherosclerosis in mice by inhibition of CD40 signalling. Nature. 1998; 394: 200-203.

19. Welt FG, Rogers SD, Zhang X, et al. GP Ilb/llla inhibition with eptifibatide lowers levels of soluble CD40L and RANTES after percutaneous coronary intervention. Catheter Cardiovasc Interv. 2004; 61: 185-189.

20. Alber HF, Frick $M$, Suessenbacher $A$, et al. Effect of atorvastatin on circulating proinflammatory T-lymphocyte subsets and soluble CD40 ligand in patients with stable coronary artery disease - a randomized, placebo-controlled study. Am Heart J. 2006; 151: 139 .

21. Tousoulis D, Antoniades C, Nikolopoulou A, et al. Interaction between cytokines and sCD40L in patients with stable and unstable coronary syndromes. Eur J Clin Invest. 2007; 37: 623-628.

22. Robertson AK, Rudling M, Zhou X, et al. Disruption of TGF-beta signaling in T cells accelerates atherosclerosis. J Clin Invest. 2003; 112: 1342-1350.

23. Zhou X, Nicoletti A, Elhage R, Hansson GK. Transfer of CD4(+) T cells aggravates atherosclerosis in immunodeficient apolipoprotein $E$ knockout mice. Circulation. 2000; 102: 2919-2922.

24. Ross R. Atherosclerosis - an inflammatory disease. New Eng J Med. 1999; 340: 115-126.

25. Glass CK, Witztum JL. Atherosclerosis: the road ahead. Cell. 2001; 104: 503-516.

26. Binder CJ, Chang MK, Shaw PX, et al. Innate and acquired immunity in atherogenesis. Nat Med. 2002; 8: 1218-1226.

27. Hansson GK. Inflammation, atherosclerosis, and coronary artery disease. New Engl J Med. 2005; 352: 1685-1695.

28. Boren J, Olin K, Lee I, et al. Identification of the principal proteoglycan-binding site in LDL. A single-point mutation in apo-B100 severly affects proteoglycan interac tion without affecting LDL receptor binding. J Clin Invest. 1998; 101: 2658-2664.

29. Gaut JP, Heinecke JW. Mechanisms for oxidizing low-density lipoprotein. Insights from patterns of oxidation products in the artery wall and from mouse models of atherosclerosis. Trends Cardiovasc Med. 2001; 11: 103-112.
30. Fredrikson GN, Soderberg I, Lindholm M, et al. Inhibition of atherosclerosis in apoEnull mice by immunization with apoB-100 peptide sequences. Arterioscler Thromb Vasc Biol. 2003; 23: 879-884

31. Pentikäinen MO, Öörni K, Ala-Korpela M, Kovanen PT. Modified LDL-trigger of atherosclerosis and inflammation in the arterial intima. J Intern Med. 2000; 247: 359-370.

32. Lusis AJ. Atherosclerosis. Nature. 2000; 407: 233-241.

33. Suzuki $H$, Kurihara $Y$, Takeya $M$, et al. A role for macrophage scavenger receptors in atherosclerosis and susceptibility to infection. Nature. 1997; 386: 292-296.

34. Hansson GK. Immune mechanisms in atherosclerosis. Arterioscler Thromb Vasc Biol. 2001; 21: 1876-1890.

35. Schonbeck U, Sukhova GK, Shimizu K, et al. Inhibition of CD40 signaling limits evolution of established atherosclerosis in mice. Proc Natl Acad Sci USA. 2000; 97 7458-7463.

36. Phipps RP. Atherosclerosis: the emerging role of inflammation and the CD40-CD40L system. Proc Natl Acad Sci. 2000; 97: 6930-6932.

37. Daugherty A, Rateri DL. T lymphocytes in atherosclerosis. The Yin-Yang of Th1 and Th2 influence on lesion formation. Circ Res. 2002; 90: 1039-1040.

38. Laurat $E$, Poirier $B$, Tupin $E$, et al. In vivo downregulation of $T$ helper cell 1 immune responses reduces atherogenesis in apolipoprotein E-knockout mice. Circulation. 2001; 104: 197-202

39. Pinderski LJ, Fischbein MP, Subbanagounder G, et al. Overexpression of interleukin- 10 by activated $T$ lymphocytes inhibits atherosclerosis in LDL receptor-deficient mice by altering lymphocyte and macrophage phenotypes. Circ Res. 2002; 90: 1064-1071.

40. Hansson GK. Vaccination against atherosclerosis: science or fiction? Circulation. 2002; 106: 1599-1601.

41. Shishehbor MH, Bhatt DL. Inflammation and atherosclerosis. Curr Atheroscler Rep. 2004; 6: 131-139.

42. Wick G, Schett $G$, Amberger A, et al. Is atherosclerosis an immunologically mediated disease? Immunol Today. 1995; 16: 27-33.

43. Kobayashi K, Tada K, Itabe H, et al. Distinguished effects of antiphospholipid antibodies and anti-oxidized LDL antibodies on oxidized LDL uptake by macrophages. Lupus. 2007; 16: 929-938.

44. Wick G, Perschinka H, Millonig G. Atherosclerosis as an autoimmune disease: an update. TRENDS Immunol. 2001; 22: 665-669.

45. Shoenfeld $Y$, Sherer $Y$, Harats $D$. Atherosclerosis as an infectious, inflammatory and autoimmune disease. TRENDS Immunol. 2001; 22: 293-295.

46. Paigen B, Plump AS, Rubin EM. The mouse as a model for human cardiovascular disease and hyperlipidemia. Curr Opin Lipidol. 1994; 5: 258-264.

47. Moghadasian MH. Experimental atherosclerosis: a historical overview. Life Sci. 2002; 70: 855-865.

48. Jawień J, Nastalek P, Korbut R. Mouse models of experimental atherosclerosis. J Physiol Pharmacol. 2004; 55: 503-517.

49. Piedrahita JA, Zhang SH, Hagaman JR, et al. Generation of mice carrying a mutant apolipoprotein E gene inactivated by gene targeting in embryonic stem cells. Proc Natl Acad Sci. 1992; 89: 4471-4475.

50. Plump AS, Smith JD, Hayek T, et al. Severe hypercholesterolemia and atherosclerosis in apolipoprotein $\mathrm{E}$ - deficient mice created by homologous recombination in $\mathrm{ES}$ cells. Cell. 1992; 71: 343-353.

51. Meir KS, Leitersdorf E. Atherosclerosis in the apolipoprotein $\mathrm{E}$ - deficient mouse. A decade of progress. Arterioscler Thromb Vasc Biol. 2004; 24: 1006-1014.

52. Savla U. At the heart of atherosclerosis. Nature Med. 2002; 8: 1209.

53. Capecchi MR. Generating mice with targeted mutations. Nature Med. 2001; 7: 1086-1090.

54. Breslow JL. Mouse models of atherosclerosis. Science. 1996; 272: 685-688.

55. Hansson GK, Libby P, Schonbeck U, Yan ZO. Innate and adaptive immunity in the pathogenesis of atherosclerosis. Circ Res. 2002; 91: 281-291.

56. Steinberg D. Atherogenesis in perspective: hypercholesterolemia and inflammation as partners in crime. Nat Med. 2002; 8: 1211-1217.

57. Fan J, Watanabe T. Inflammatory reaction in the pathogenesis of atherosclerosis. J Atheroscler Thromb. 2003; 10: 63-71.

58. Libby P. Changing concepts of atherogenesis. J Intern Med. 2000; 247: 349-358

59. Libby P. Inflammation in atherosclerosis. Nature. 2002; 420: 868-874.

60. Libby P, Ridker PM, Maseri A. Inflammation and atherosclerosis. Circulation. 2002; 105: 1135-1143.

61. Jawień J, Gajda M, Rudling $M$, et al. Inhibition of five lipoxygenase activating protein (FLAP) by MK-886 decreases atherosclerosis in apoE/LDLR-double knockout mice. Eur J Clin Invest. 2006; 36: 141-146.

62. Alpert JS, Thygesen K. A new global definition of myocardial infarction for the $21 \mathrm{st}$ century. Pol Arch Med Wewn. 2007; 117: 485-486. 